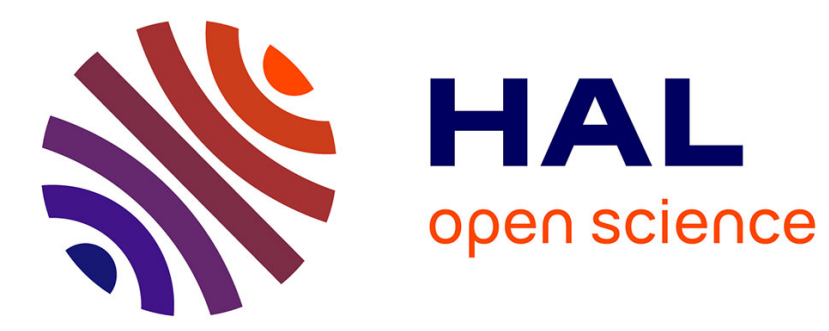

\title{
Modelling the Crash Response of Composite Structures
}

\author{
A. Johnson, D. Kohlgrüber
}

\section{To cite this version:}

A. Johnson, D. Kohlgrüber. Modelling the Crash Response of Composite Structures. Journal de Physique IV Proceedings, 1997, 07 (C3), pp.C3-981-C3-986. 10.1051/jp4:19973165 . jpa-00255455

\section{HAL Id: jpa-00255455 https://hal.science/jpa-00255455}

Submitted on 1 Jan 1997

HAL is a multi-disciplinary open access archive for the deposit and dissemination of scientific research documents, whether they are published or not. The documents may come from teaching and research institutions in France or abroad, or from public or private research centers.
L'archive ouverte pluridisciplinaire HAL, est destinée au dépôt et à la diffusion de documents scientifiques de niveau recherche, publiés ou non, émanant des établissements d'enseignement et de recherche français ou étrangers, des laboratoires publics ou privés. 
J. PHYS IV FRANCE 7 (1997)

Colloque C3, Supplément au Journal de Physique III d'août 1997

C3-981

\title{
Modelling the Crash Response of Composite Structures
}

\author{
A.F. Johnson and D. Kohlgrüber
}

German Aerospace Establishment (DLR), Institute of Structures and Design, 70569 Stuttgart, Germany

\begin{abstract}
The paper describes recent progress on the materials modelling and numerical simulation of the dynamic crash response of fibre reinforced composite structures. The work is based on the application of explicit finite element analysis codes to composite aircraft structures and structural elements under low velocity impact conditions (up to 15 $\mathrm{m} / \mathrm{s}$ ). Structures studied are designed to absorb crash energy and reduce seat deceleration pulses in aircraft subfloor structures, and consist of an aircraft keel beam concept for an executive aircraft and hybrid carbon/aramid helicopter subfloor box structures. Comparison between predicted structural response and failure modes with observed test results are given in each case.
\end{abstract}

Résumé. Cette communication décrit les prog̣ès récents effectués dans le domaine de la modélisation des matériaux ê de la simulation numérique du comportement d'éléments de structure en composite lors d'un crash. Cette étude est basée sur l'application de la méthode des éléments finis à ces élements de structure avion dans le cas d'impact à basse vitesse (jusqu'à $15 \mathrm{~m} / \mathrm{s}$ ). Les structures étudiées (longerons inférieurs de la carlinģue d'un avion d'affaires et les longerons de la structure inferielire d'un hélicoptère) sont conçues de manière à absorber le maximum d’énérgeie du crash et par conséquent à réduire l'interisité du pic de décéleration. Les résultats des simulations sont ensuite comparés aux essais effectués.

\section{INTRODUCTION}

Composite materials are now being used in primary aircraft structures, particularly in helicopters, light aircraft, commuter planes and sailplanes, because of advantages such as light weight, high static and fatigue strength and their formability into large integral shell structures. However materials such as carbon fibre/epoxy are inherently brittle and may exhibit a linear elastic response up to failure with little or no plasticity. Thus before these materials are used more extensively in larger passenger carrying aircraft structures it is important to understand energy absorption and failure mechanisms, to have tools for assessing the crashworthiness of such structures, and to consider whether special energy absorbing substructures or seats are required to maintain occupant safety levels.

Conventional metallic structures absorb crash energy through plastic hinge formation and the folding or collapse of shell and beam elements. Modern commercial finite element (FE) codes, developed for automotive crash simulations, are able to model these effects and have recently been successfully applied to simulate the failure of riveted aluminium aircraft fuselage structures under low velocity impact loads [1], [2]. This paper is concerned with the validity of such codes for modelling the crash response of composite aircraft structures. Emphasis is given to composites materials models suitable for implementation into FE codes, which can adequately characterise the damage progression and failure modes which occur in composites. Most research on composite properties is on unidirectionaliy (UD) reinforced laminates, however in actual structures fabric reinforcements are more common. In §2 suitable mechanical models and relevant test data for fabric reinforced composite laminates are discussed. These are based on an orthotropic elastic damaging materials model, in which a scalar damage parameter is introduced to describe materials nonlinearity.

Some recent examples of FE simulations with PAM-CRASH [3] on the impact response of aircraft subfloor structures based on this materials model are then described. In $\S 3$ an energy absorbing (EA) sandwich beam concept for the aircraft keel beam of an executive jet, designed to reduce deceleration pulses on the seats, is analysed under impact loads. Section 4 is concerned with helicopter subfloor box structures fabricated from hybrid carbon/aramid fabric composites. Here the critical elements are cruciform nodes which connect the longitudinal and transverse floor beams. Comparison between predicted dynamic response and failure modes with observed test results are given in each case. 


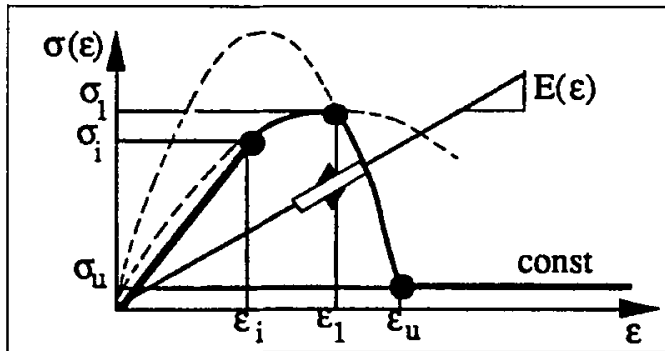

Fig. 1 Idealised stress-strain curve for composites

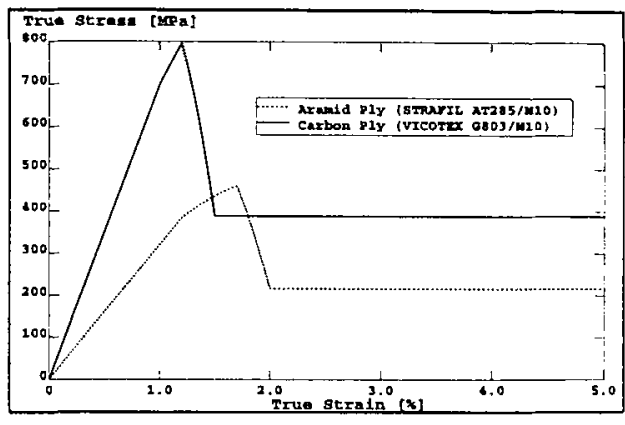

Fig. 2 Ply properties in compression for FE model

\section{MODELLING COMPOSITES PROPERTIES}

For metals there is extensive information in the literature on dynamic materials properties at large strains and high strain rates, see for example [4]. Constitutive equations such as the Cowper-Symons law for modelling the rate dependent, strain hardening behaviour of steel and aluminium under high rate loading have been implemented into dynamic FE codes such as PAM-CRASH for structural impact simulations. For composite materials dynamic failure behaviour is very complex due to the different fibres and matrices available, the different fibre reinforcement types such as unidirectional (UD) fibres and fabrics, the possibility of both fibre dominated or matrix dominated failure modes, and the rate dependence of the polymer resin properties. Thus at present there are no universally accepted materials laws for crash simulations with composites, although specific composites models have been implemented in some of the commercial FE codes.

PAM-CRASH contains several materials models and special elements for laminated composite materials, which are discussed in [5]. These have been developed mainly for UD laminates and have not been specifically validated for fabric laminates, which are the reinforcements of interest here. It was considered that a homogeneous orthotropic elastic damaging material was the most appropriate model for fabric laminates, as this model is applicable to brittle materials whose properties are degraded by microcracking. This type of material may be modelled in PAM-CRASH as a 'degenerate bi-phase' model in which the UD fibre phase is omitted, and the 'matrix' phase is assumed to be orthotropic. The assumed stress-strain relation in the model then has the general orthotropic form

$$
\sigma=\mathbf{E} \varepsilon, \quad \mathbf{E}=\mathbf{E}_{\mathbf{o}}\left[1-\mathrm{d}\left(\varepsilon_{\mathrm{II}}\right)\right],
$$

where $\sigma, \varepsilon$ are the stress and strain tensors, $\mathbf{E}$ the stiffness matrix with initial values $\mathbf{E}_{\mathbf{0}}$, and $\mathrm{d}$ is a scalar damage parameter. This takes values $0<\mathrm{d}<1$ and is assumed to be a function of the second strain invariant $\varepsilon$ II, or the effective shear strain. The composite fabric ply or laminate has orthotropic stiffness properties, but a single 'isotropic' damage function which degrades all the stiffness constants equally. Such a materials model has been used successfully to simulate the crash response of a quasi-isotropic carbon fabric/epoxy airframe structure in [6]. Here it is applied in a pragmatic way to a number of orthotropic and quasi-isotropic fabric composite laminated structures.

Uniaxial stress-strain curves for fabric reinforced composites are modelled by a bilinear damage function, in which there are two damage constants $d_{1}$ and $d_{u}$ to be determined and the general uniaxial stress-strain curve has the general form shown in Fig. 1, where $\varepsilon_{i}$ is strain at the onset of initial damage, $\varepsilon_{1}$ is the strain at the peak failure stress, and $\varepsilon_{\mathrm{u}}$ is a limiting strain above which the stress is assumed to take a constant value $\sigma_{u}$. Typical stress-strain curves for fabric composites in tension and compression are in this general form and can be used to calibrate the materials model and to determine the damage parameters $\mathrm{d}_{1}$ and $\mathrm{d}_{u}$ for the analysis. The parameter $d_{1}$ measures the departure from linearity at the first knee in the stressstrain curves, and is thus small in tension, whilst the parameter $d_{u}$ determines the residual value $\sigma_{u}$. For the FE analysis it is not good practice to reduce the material stresses directly to zero at material fracture, as this may lead to numerical instabilities. Thus under tensile stresses typically $\mathrm{d}_{\mathrm{u}} \cong 0.9$, indicating that the element is nearly fully damaged, whilst in compression $\mathrm{d}_{\mathrm{u}} \cong 0.5$ to model the compression crush stress allowing the element retains a load carrying capability after initial damage.

The composites structures studied in the paper have been designed for high EA, and consist of hybrid laminates of glass and aramid fabric/epoxy for the sandwich beams of $\$ 3$, and carbon and aramid 
fabric/epoxy in the subfloor elements of $\S 4$. Thus a materials specimen test programme is necessary to determine the basic mechanical properties of the aramid, glass and carbon fabric/epoxy ply materials used. This test programme is not yet complete, however sufficient data were available to estimate values for the main parameters required by the elastic damaging materials model, with further materials properties such as additional elastic constants being determined from in-house data or laminate analyses. Fig. 2 shows typical stress-strain curves in the model for the aramid and carbon fabric/epoxy materials loaded in compression along the fibre directions. Both curves are in the general form of Fig. 1, with compression crush strengths chosen to be $50 \%$ of the compression strength values, and failure strains in the aramid ply about twice as high as those in the carbon ply. Although composites exhibit some rate dependence in properties, this effect is not considered to be very significant in low velocity impacts, and was not included in the modelling presented here.

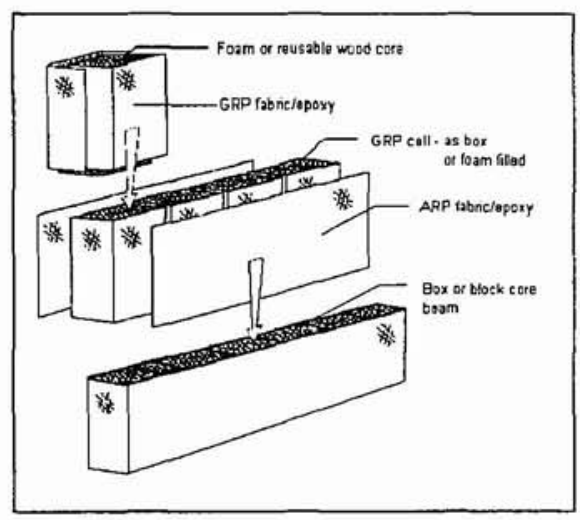

Fig. 3 Construction of box core beams

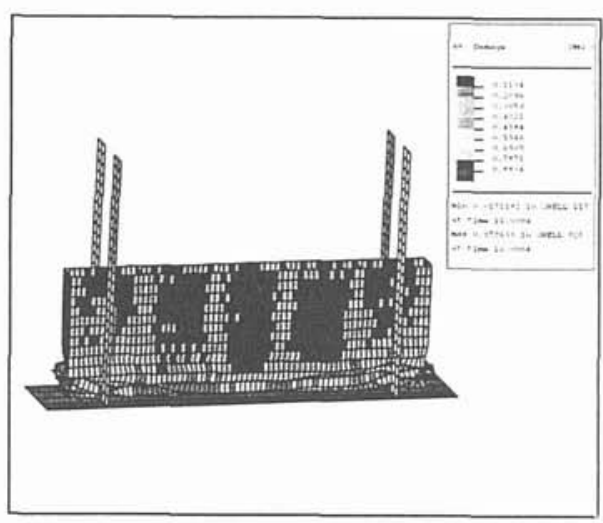

Fig. 4 Fe simulation of box core beam in impact

\section{DYNAMIC CRUSH BEHAVIOUR OF SANDWICH FLOOR BEAMS}

Crash tests carried out by NASA on general aviation $(\mathrm{GA})$ aircraft with a carbon fibre/epoxy composite fuselage structure [7] have shown that seat deceleration pulses are generally twice as high as those in a similar aluminium aircraft and too high for occupant safety. To meet current safety recommendations it is necessary to install safety seats and/or EA keel beams to support the seat rails. This led NASA to develop a modular EA floor beam concept for GA aircraft based on sandwich webs with glass and aramid fabric/epoxy faces and hollow GRP box cores or foam filled block cores, see Fig. 3. Kellas [8] describes in detail the beam design and fabrication concept, and has fabricated and impact tested box core and block core beams with 10 different cell geometries and skin layups, which demonstrated the success of this light weight EA beam concept. As Fig. 3 shows the beams themselves have a simple modular construction based on composite boxes, with or without foam cores, and by varying geometry and ply layup in the cells a wide range of floor beams with different stiffnesses and EA properties can be produced. In order to select and optimise these floor beams, a design tool has been developed based on a modular FE model of the beams under static and dynamic loads. One aspect of the beam design method concerned FE simulations with PAM-CRASH [3] to determine failure modes and energy absorption in the beams under crash loads. Some typical results of the dynamic simulations are presented in this section on four selected beam constructions tested in [8].

In the nomenclature of [8] the beams are referred to as Box $3 \& 4$, and Block $3 \& 4$. All 4 beams have length $300 \mathrm{~mm}$, height $200 \mathrm{~mm}$, and thickness $25 \mathrm{~mm}$, and consist of 5 cells with rectangular cross-section 60 $\mathrm{mm} \times 25 \mathrm{~mm}$. The block core beams are identical to the corresponding box core beam, but with the addition of a foamed PVC core. Box 3 and Block 3 contain glass fabric/epoxy (GRP) plies with fibres aligned at $\pm 45^{\circ}$ to the box cell axes, whilst Box 4 and Block 4 have the glass fabric/epoxy with fibres at $0 / 90^{\circ}$ to the box cell axes. The boxes are assembled as shown in Fig. 3, then the aramid fabriclepoxy (ARP) faceplates are added with fibres at $\pm 45^{\circ}$ to the box cell axes. The laminate thickness depends on the beam fabrication method. For the GRP and ARP materials used a single ply has a nominal thickness of $0.25 \mathrm{~mm}$. Reference to the beam 
construction shown in Fig. 3, indicates that the beam face sheets consist of 2 plies with GRP internal and ARP external, the end plates contain 2 GRP plies, and the internal webs contain 4 GRP plies.

The FE model of the box core beams contained about 5000 4-node layered shell elements to model the composite laminates. For the block core beams an additional 20000 8-node solid elements were added to model the foam core. It was assumed that the shell elements are attached to the outer faces of the solid elements, with common nodes. In the axial impact tests on the box core sandwich beams a rigid mass is attached to the top edge of the beam and they are accelerated downward onto a rigid base plate. In the PAMCRASH model the beam was placed on a rigid wall and an impacting mass of $45 \mathrm{~kg}$ was distributed over the top edge nodes, which were additionally coupled in the axial direction and given an initial impact velocity. The impact velocities were chosen to be the same as in the tests and varied from $7.8-9.1 \mathrm{~m} / \mathrm{s}$. The test beams were supported laterally by two sets of knife edges, which were modelled as rigid plates. Materials specimen tests were carried out to measure the basic materials properties required for the FE materials model discussed in $\$ 2$. Since in impact the ARP plies are loaded principally at $45^{\circ}$ to the fibre direction, the damage parameters were determined from tests on $45^{\circ}$ specimens. When loaded in this direction ply properties are dominated by in-plane shear behaviour which leads to failure strains of about $5 \%$ in the GRP plies and $10 \%$ or higher in the ARP plies. These high failure strains in the ply materials in the main load direction help explain the failure modes observed in the beams, which were by folding of the side walls rather than the expected material fracture. Test data were also available on the PVC foams based on foam block compression tests. The foam was then modelled in PAM-CRASH as an elastic-plastic solid with a yield stress.

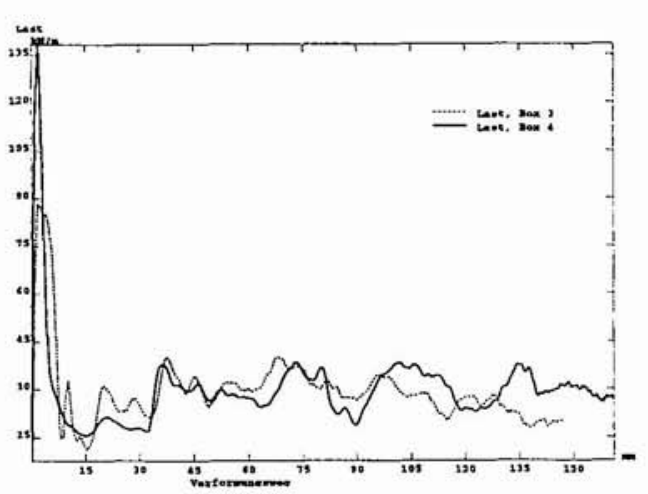

Fig. 5 Computed load-deflection response of Box 3 and Box 4 beams impacted at $7.8 \mathrm{~m} / \mathrm{s}$

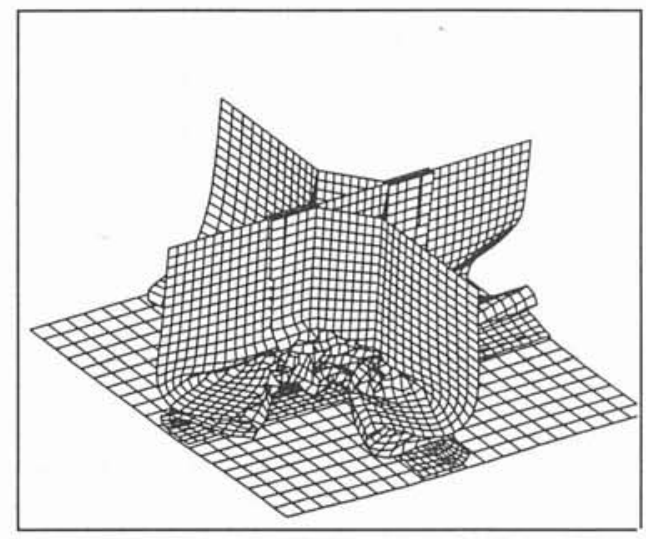

Fig. 6 FE simulation of cruciform element impacted at $10 \mathrm{~m} / \mathrm{s}$

The results of the PAM-CRASH simulations showed very satisfactory agreement with the beam tests reported in [8]. As the impact progressed the sidewalls collapsed in a folding mode as seen in Fig. 4 which shows the deformed Box 4 beam with the folds forming at the base, which is qualitatively the same as the observed failure modes in the impact tests, see [8, Fig. 11]. Fig. 5 shows the computed load-deformation response in the Box 3 and Box 4 beams. After a very high initial peak load, the dynamic crush load oscillates about at an approximately constant load level, which is a typical dynamic response of structures which fail by plastic hinge formation. The load-deflection curves have the same form as test data presented in [8]. A detailed comparison shows that the simulated initial peak is higher than the measured peak, however the mean loads and energy absorption predicted in the simulation are very similar to those measured, as can be seen in Table 1. The table lists the crush initiation loads (CIL), the steady crushing loads (SCL) and the energy absorbed $\left(\mathrm{E}_{\mathrm{ABS}}\right)$ from tests and simulations for 4 beam structures. It is seen that the simulated peak $\mathrm{CIL}$ loads are well above the test loads, although the comparison here is critically dependant on the filtering used in both the test and simulation. More important is the generally good agreement between the crush loads and energy absorbed. The table shows in the final column the ratio of SCL from simulation and test, which are seen to be within $17 \%$ of each other. Thus we conclude that the PAM-CRASH code for crash simulations is a valuable design analysis tool for understanding and optimising the properties of these modular floor beams. 
Table 1 Comparison of measured loads and energy absorption from tests and simulations (CIL crush initiation load, SCL steady crush load, $\mathrm{E}_{\mathrm{ABS}}$ energy absorbed)

\begin{tabular}{|c|c|c|c|c|c|c|c|}
\hline \multirow{2}{*}{$\begin{array}{l}\text { Beam } \\
\text { type }\end{array}$} & \multicolumn{3}{|c|}{ Simulation with PAM-CRASH } & \multicolumn{3}{|c|}{ NASA dynnamic tests [8] } & \multirow{2}{*}{$\begin{array}{c}\mathrm{SCL}_{\mathrm{PC}} / \\
\mathrm{SCL}_{\mathrm{NASA}} \\
{[\%]}\end{array}$} \\
\hline & $\begin{array}{c}\mathrm{CIL} \\
{[\mathrm{kN} / \mathrm{m}]} \\
\end{array}$ & $\begin{array}{c}\mathrm{SCL} \\
{[\mathrm{kN} / \mathrm{m}]} \\
\end{array}$ & $\begin{array}{r}\mathrm{E}_{\mathrm{ABS}} \\
{[\mathrm{kJ}]} \\
\end{array}$ & $\begin{array}{c}\text { CIL } \\
{[\mathrm{kN} / \mathrm{m}]} \\
\end{array}$ & $\begin{array}{c}\mathrm{SCL} \\
{[\mathrm{kN} / \mathrm{m}]}\end{array}$ & $\begin{array}{c}E_{\text {ABS }} \\
{[\mathrm{kJ}]} \\
\end{array}$ & \\
\hline Box 3 & 83.31 & 26.96 & $1.3 \mathrm{I}$ & 67.55 & 27.23 & 1.40 & 99 \\
\hline Box 4 & 138.30 & 28.70 & 1.38 & 52.08 & 26.36 & 1.47 & I09 \\
\hline Block 3 & 108.00 & 35.67 & 1.36 & 90.82 & 42.96 & 1.81 & 83 \\
\hline Block 4 & 166.23 & 46.13 & 1.41 & 103.87 & 44.20 & 1.49 & 104 \\
\hline
\end{tabular}

\section{CRASH RESPONSE OF HELICOPTER SUBFLOOR BEAMS}

A helicopter design concept which meets the structural and crashworthiness requirements should provide a protective shell for the occupants, with energy absorbing elements incorporated in the landing gear, the subfloor and the seats. The subfloor typically consists of a framework of longitudinal beams and lateral bulkheads covered by the outer skin and cabin floor. The total structural height is often only about $200 \mathrm{~mm}$. The design of intersections (cruciforms) of beams and bulkheads, the beam webs, outer skins, and floor sections (boxes) contribute essentially to the overall crash response of a helicopter subfloor assemblage. A versatile FE model has been developed which allows different beam and cruciform elements to be used within a subfloor box, so that both the static structural integrity and the dynamic crush response of a range of different boxes may be simulated. In this section the dynamic crush response of some typical composite subfloor elements are simulated with PAM-CRASH [3], as part of the design validation process.

The FE model of the cruciform intersection element contained about 5200 4-node orthotropic layered shell elements to simulate the hybrid composite laminates, together with 22 rigid body elements which simulated the rivets in the structure. A rivet failure model was not used, since in tests rivet failures never occurred. Structural tests on the cruciforms are carried out in a drop weight tower where the upper edges are embedded in an aluminium plate, which is impacted at about $10 \mathrm{~m} / \mathrm{s}$ by a $100 \mathrm{~kg}$ mass. In the model the nodes of the upper edges form a rigid body with an added mass of $100 \mathrm{~kg}$ at the centre of gravity, and the base plate was modelled as a rigid wall. The cruciform element is designed to absorb energy under vertical impact loads, thus the composite materials selected are hybrid laminates of carbon and aramid fabric/epoxy. The materials model appropriate to these fabric reinforced laminates is the orthotropic elastic damaging material discussed in $\S 2$. The laminate construction varied between different plate elements in the cruciform, for example in the transverse floor beam direction the laminate construction is a symmetric hybrid 8 ply layup [A45/A45/C45/C0]S, where $A$ and $C$ refer to aramid and carbon fabric prepregs and the subscript is the fabric angle to the vertical direction. Tensile test specimen data on the ply materials were used to generate stressstrain curves and suitable values for the elastic constants and damage parameters in the materials model were determined. Additional materials data required by the PAM-CRASH model were estimated. For example, Fig. 2 shows the assumed stress-strain response in compression for the carbon and aramid fabric/epoxy ply materials used in the cruciforms.

The results of the dynamic simulations of vertical impacts on the cruciform elements showed excellent agreement between the predicted modes of failure and those observed in tests. In tests the element fails by regular folding of the vertical webs in contact with the base plate, initiated by the J-trigger at this position. This is clearly seen in Fig. 6 in the FE simulation after $12 \mathrm{~ms}$. Folding failures occur because of the hybrid laminate chosen, in which the more ductile aramid fabric plies are on the outer faces where the bending stresses are higher, which seems to inhibit brittle failures associated with carbon fibre composites. Fig. 7 compares the predicted load-deflection response under impact compared with test data on 3 hybrid cruciform elements. One of the tests was performed quasi-statically, the other two were impact tests in a drop weight tower. There was not a significant difference between the quasi-static and dynamic test data. There is general agreement in the shape of the load-deflection curves between test and simulation. However the load levels, and hence the total energy absorbed in the simulations, are typically about $50 \%$ below the test results, which shows that further improvements are required in the dynamic modelling of these hybrid laminates. More detailed materials specimen tests are currently being carried out in compression and shear on the carbon and aramid ply materials, as a basis for improvements to the materials models in the FE simulation. 


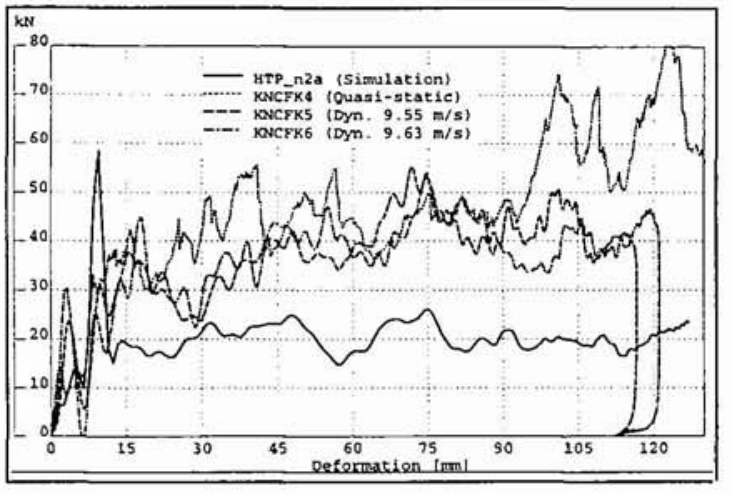

Fig. 7 Load-deflection response of cruciforms under impact (comparison test results and FE simulation)

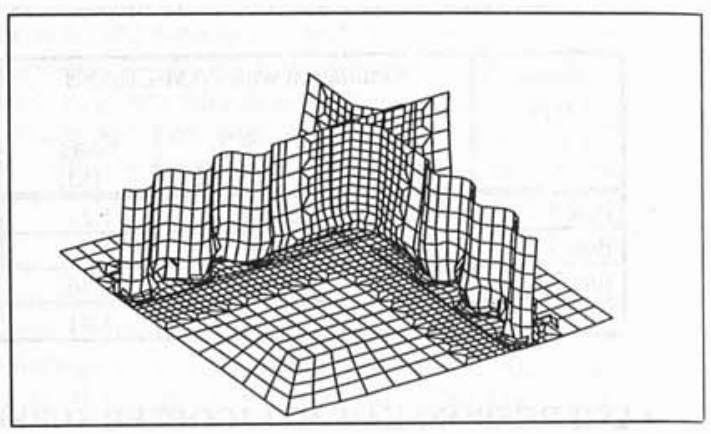

Fig. $8 \mathrm{FE}$ simulation of subfloor box under impact at $10 \mathrm{~m} / \mathrm{s}$

As a further example of the design procedure, a subfloor box was simulated dynamically which corresponds to the box test series discussed above. The box consisted of 4 cruciform elements, connected by 4 sine-wave web beam elements and fabricated from hybrid carbon/aramid fabric laminates. The simulation conditions of vertical impact at $10 \mathrm{~m} / \mathrm{s}$ and the materials modelling were as described above for the cruciform element. Simulation results for the quarter deformed box after $8 \mathrm{~ms}$ are shown in Fig. 8. We see that the cruciform element fails again in the local folding mode, whilst the sine-wave beam elements fail in a high energy absorbing crushing mode initiated by triggers at the floor intersection. Simulations of helicopter subfloor boxes with other beam configurations showed different failure modes, such as plate buckling in rib stiffened webs, which have much lower EA properties. Thus PAM-CRASH simulations could be used as at design tool for the selection of suitable elements in the subfloor structure.

\section{CONCLUSIONS}

The paper has presented a materials model for composite shell elements with fibre fabric reinforcement, which is implemented in the dynamic FE code PAM-CRASH. Simulation of composite subfloor beam structures for GA aircraft and helicopters under low velocity crash loading conditions have been performed to validate the code and materials models. Good agreement was obtained with crush loads and energy absorption for glass/aramid/epoxy sandwich beams. In a more complex helicopter subfloor structure with carbon/aramid hybrid laminates, failure modes were well modelled but predicted loads and energy absorption were too low. Thus improvements are required in the ability to predict accurately energy absorption and peak crushing loads in more complex structures. It is thought that these will result from implementation into dynamic FE codes of more accurate composites materials failure models, and improvements in the measurement of dynamic composites properties at large strains. Both these aspects are being addressed in ongoing work.

\section{References}

[1] Johnson, A.F., Kindervater, C.M., Kohlgrüber, D. and Lützenburger, M., "Predictive Methodologies for the crashworthiness of aircraft structures," American Helicopter Society 52nd Annual Forum (1996), Washington DC.

[2] Hashemi, S.M.R., Sadeghi, M.M., Walton,A.C., "Modelling verification of an airframe section and comparison with impact test", Int. J. Crashworthiness, 1 (1996) 11-20.

[3] PAM-CRASH, Engineering Systems International SA, F-94588 Rungis, France.

[4] Jones, N. Structural Impact, Cambridge University Press, (1989).

[5] Haug, E., de Rouvray, A., "Crash response of composite structures", Ch. 7 "Structural crashworthiness and failure" (1993) (ed) N. Jones and T. Wierzbicki, Elsevier, London.

[6] Johnson, A. F., "Modelling the crash response of a composite airframe section", ICCM-10, (1995) Whistler, Canada.

[7] Jones, L.E., Carden, H.D., "Overview of structural behaviour and occupant responses from acrash test of a composite airplane", SAE General Aviation Meeting, Kansas (1995).

[8] Kellas, S., "An experimental investigation into the EA performance of composite beam webs for aircraft subfloor applications". American Helicopter Society National Technical Specialists' Meeting on Rotorcraft Structures (1995) Williamsburg. 